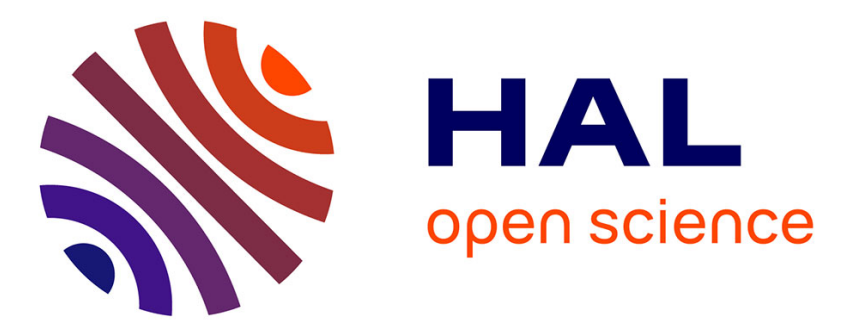

\title{
Factors Preventing the Social Reintegration of Homeless Persons: A Comparison Between Residents of Long-Stay Hostels and Individuals Living on the Street
}

\author{
Gaétan Langlard, Evelyne Bouteyre Verdier, Amine Rezrazi
}

\section{- To cite this version:}

Gaétan Langlard, Evelyne Bouteyre Verdier, Amine Rezrazi. Factors Preventing the Social Reintegration of Homeless Persons: A Comparison Between Residents of Long-Stay Hostels and Individuals Living on the Street. Social Work in Mental Health, 2019, 17 (2), pp.237-252. 10.1080/15332985.2018.1547243 . hal-02437469

\author{
HAL Id: hal-02437469 \\ https://hal.science/hal-02437469
}

Submitted on 13 Jan 2020

HAL is a multi-disciplinary open access archive for the deposit and dissemination of scientific research documents, whether they are published or not. The documents may come from teaching and research institutions in France or abroad, or from public or private research centers.
L'archive ouverte pluridisciplinaire HAL, est destinée au dépôt et à la diffusion de documents scientifiques de niveau recherche, publiés ou non, émanant des établissements d'enseignement et de recherche français ou étrangers, des laboratoires publics ou privés. 
Factors Preventing the Social Reintegration of Homeless Persons: A Comparison Between Residents of Long-Stay Hostels and Individuals Living on the Street

\author{
Gaétan LANGLARD $^{1 ; 2}$; , Evelyne BOUTEYRE ${ }^{2}$, Amine REZRAZI ${ }^{1}$ \\ ${ }^{1}$ EA 7475, Laboratory CRFDP, University of Rouen, 76821 Mont-Saint-Aignan, France \\ ${ }^{2}$ EA 3278, Laboratory LPCPP, University of Aix-Marseille, 13331 Aix-en-Provence, France \\ * Corresponding author : gaetan.langlard@gmail.com
}

Langlard, G., Bouteyre, E., \& Rezrazi, A. (2019). Factors preventing the social reintegration of homeless persons: A comparison between residents of long-stay hostels and individuals living on the street. Social Work in Mental Health, 17(2), 237-252. 


\begin{abstract}

\section{Objective}

Homelessness is a major social issue in all Western countries. In France, many homeless persons do not have access to the accommodation and help with social reintegration provided in longstay hostels, and remain on the streets or in other forms of emergency shelter. The objective of the present study was to identify the variables preventing access to these hostels and, more generally, to a process of social reintegration.
\end{abstract}

\title{
Method
}

We compared a group of 10 individuals housed in long-stay hostels with a group of 16 who were still living on the street. All participants were assessed on the Hospital Anxiety and Depression Scale (Zigmond \& Snaith, 1983) and underwent a semistructured interview.

\section{Results}

Results showed that individuals who had not been admitted to a hostel were characterized by high levels of depression and anxiety, the attribution of responsibility to external factors, a vagrant lifestyle, a lack of social support, a negative approach to reintegration, and an inability to look to the future.

\section{Conclusion}

This study highlights various factors explaining the reintegration difficulties encountered by a proportion of the homeless population. It suggests new ways of improving support for the homeless.

Keywords: homeless, mental health, mental disorders, rehabilitation, psychosocial distress, exclusion 


\section{Introduction}

Marginalized people have always existed. Depending on the time and place, they have been variously called vagabonds, tramps, beggars, itinerant people, homeless people... Since the 80's, they are usually referred to as the Homeless (SDF). This category is composed of a wide range of individuals with various historical background and very different lifestyles. Some of them suffer from a strong lack of job security. Others, who are less excluded from society, are poor workers or homeless couples. The variety of situations and individuals makes it difficult both to gather data and to interpret the results obtained. Epidemiological studies also suffer from the variety of observed situations and the difficulty of handling the data. For example, the results from studies concerning the prevalence of psychiatric troubles in the homeless population cannot be properly compared with each other (Fazel, Khosla, Doll, \& Geddes, 2008; Fichter \& Quadflieg, 2001; Guesdon \& Roelandt, 1998; Kovess \& Mangin Lazarus, 1999). Besides the fact that different methodologies have been used, these studies massively depend on the location where the data have been gathered (on the street, in a hostel, a refuge, in a rehabilitation center or food center, etc.). Nevertheless, a general consensus does stem from these studies. They demonstrate an increased morbidity resulting from psychiatric disorders among the Homeless, especially with depression, anxiety, psychosis and all the consequences of alcoholism and drug-addiction (American psychiatric association, 1995). This finding leads to the following question (Cohen \& Thompson, 1992) : is this increased psychiatric morbidity the cause of street-life conditions for homeless people, or is it the consequence of a lack of care from the healthcare service? This questions remains without an answer. It leaves moot the question of the alleged link between social exclusion and mental illness (Bassuk, Rubin, \& Lauriat, 1984). 
In parallel with those epidemiologic studies, numerous authors deal with the effects of social exclusion in terms of desocialization (Vexliard, 1957), disaffiliation (Castel, 1995), precariousness (Wresinski, 1987), over-adaptation (Chevalier, Langlard, Le Maléfan, \& Bouteyre, 2017), homeless careers (Chamberlain \& MacKenzie, 2006), and the pathways approach (Clapham, 2003). Others describe phenomena such as vagrancy, living from day to day, a deficit in psychic elaboration (Benslama, 2005; Langlard, 2017). The emphasis is placed on the loss or weakening of social bonds (Vandecasteele \& Lefebvre, 2006).

Every Western country has to deal with the issue of homeless people, which has become a major societal problem over the past ten years. In order to contain homelessness France implemented a wide range of social help policies which aim at leading the whole homeless population to social reintegration. The first part of this program corresponds to emergency shelter and is an answer to the necessity of dealing with situations requiring immediate assistance. As emergency shelter can't be an end in itself, it must be as short as possible and enable an orientation towards a solution more adapted to the person. The Centres d'Hébergement et de Réinsertion Sociale (CHRS) are supposed to answer these questions of accomodation and to offer to take care of the people in need longly enough to enable their reinsertion and their return to work and housing.

Ideally successive, the actions of emergency accomodation and of insertion are in reality inefficient. Though most of the homeless should be able to acceed to the CHRS, in fact insidious criteria of admission operate within the structures with the result that only the most employable among them have access to that stage of the program.On the opposite, the most desocialized homeless as well as those who suffer from mental illness or alcoholism settle in emergency accomodation or in street living.

To explain the obstacles to social reintegration, certain authors have cited the impact of psychiatric disorders (Combaluzier \& Pedinielli, 2003) and the reluctance of individuals to use 
emergency shelters (Langlard \& Bouteyre, 2013; Noirot, Descarpentries, \& Mercuel, 2000). Another issue is the question of causal attribution (Heider, 1958), where an event is explained in terms of either internal or external causality. Beauvois and Dubois (1988) and Testé (2009) highlighted the existence of an internality norm in Western societies. Reflected in the welfare system, this norm means that a sense of responsibility and autonomy becomes a prerequisite for social reintegration (Astier, 2007; Duvoux, 2009). It is because of these expected qualities that many authors (Damon, 2002; Soulié, 1997) believe that the conditions for being admitted to a CHRS are too selective, and thus unsuitable for a proportion of the homeless population.

The purpose of the present comparative study was to shed light on the issue of the social reintegration of homeless people. It was based on a comparison between a group of 10 homeless persons residing in CHRSs, and another group of 16 homeless persons who were not part of any reintegration process. We focused on the following questions:

- Do these two groups differ on levels of depression and anxiety?

- What are the differences and similarities between the two groups in terms of lifestyle, the subjective responsibility they attribute to their situation, the support they receive from family or friends, their attempts to reintegrate society, and their perceptions of the future?

\section{Method}

\subsection{Sample}

Participants were homeless, French-speaking male adults. They were recruited in Rouen, a city in northern France with 110,000 inhabitants. In order to take part in the study, they all had to be able to communicate verbally and be willing to establish contact with other people. The present study was conducted in accordance with the Declaration of Helsinki. Every 
participant gave his informed consent to complete a psychometric scale and undergo a recorded interview. Two groups were formed and compared.

The first group was made up of 10 homeless persons living in a CHRS. To receive social help and be given accommodation in a hostel, homeless individuals have to submit an application to a local commission. If their request is granted, a reintegration project is drawn up, followed by a social support contract, the ultimate goal being resettlement and employment. While such structures are initially addressed to all of the homeless population, admission is in fact highly selective. The individuals must be able to respect the rules of living, to put an end to their errant behavior and massive alcoholism, and to elaborate a project of insertion as well as to wait several months before a place comes available. These hostels offer full board and lodging in individual rooms. The support given to users lasts for a renewable 6-month period, and they are asked to make a financial contribution (proportionate to their means). The participants’ mean age was 35.6 \pm 13.9 years. They were encountered between December 2011 and January 2012. Meetings and questionnaires were organized in a room in their hostel.

- The second group was made up of 16 homeless persons, with a mean age of $45.4 \pm$ 12.9 years. These participants were not part of any social reintegration process. Eight of them were encountered at a night shelter between June and September 2010 (i.e., during the summer). This shelter only accepts single men of adult age, between the hours of 6 pm and 9 am, and offers dormitory accommodation. It can cater for 120 persons. Admission is unconditional and immediate, as long as the user called the 115 emergency helpline. The meetings and questionnaires were organized in the shelter's offices. Eight other participants lived exclusively on the street. They were encountered between November 2010 and January 2011 (i.e., during the winter). Some of them were recruited during patrols organized by the Social emergency service (SAMU Social) of the French Red Cross, while others were recruited at a soup kitchen 
open to all at lunchtimes. Meetings and questionnaires took place in bars during quiet hours for more privacy.

\subsection{Instruments}

\subsubsection{Hospital Anxiety and Depression Scale}

The Hospital Anxiety and Depression Scale (Zigmond \& Snaith, 1983; French translation: Lepine, Godchau, Brun, \& Lempérière, 1985) is a mixed scale in the form of a questionnaire containing 14 items (7 for anxiety and 7 for depression) measured on a Likertlike scale ranging from 0 to 3 (inter-rater reliability $=0.88$; stability $=0.85$ ). It enabled us to assess the degree of depressive and anxious symptoms in each participant. A total score of 11 or more indicated an obvious anxious or depressive state (within the framework of our study), and a score between 8 and 10 a possible anxious or depressive state. This rapid test is particularly useful for homeless people, as it eliminates the influence of somatic symptoms such as diet or sleep quality.

\subsubsection{Semistructured interview}

Each participant underwent a semistructured interview. This interview probed the degree of subjective responsibility they attributed to their situation, as well as the support they received from family and friends, their lifestyle, their attempts at social reintegration, and their perceptions of their future.

\subsection{Statistical Analysis}

The statistical analyses were conducted with SPSS software, version 19. 
Anxiety and depression scores were subjected to analyses of variance (ANOVAs; one for each factor). The homogeneity of variance had previously been tested with Levene's statistic.

Analysis of the data collected during the interviews made it possible to gain precise information about the participants' way of life, their social relationships, and their vision of the future. We then crossed the admission condition variable (admitted to a CHRS vs. not admitted to a CHRS), and the precise information variable with two modalities (provided by the participant vs. not provided by the participant). The association between these two variables was studied with the chi-squared test.

\section{Results}

\subsection{Anxiety and Depression Scores}

Table 1 sets out the mean scores and standard deviations (SDs) for depression and anxiety for both groups of participants. The higher the score, the deeper the depressive or anxious state.

\section{Insert Table 1 here}

There were significant differences in the mean scores for depression between the two groups, $F(1,24)=4.66, p<0.05$. The homeless participants who were not accommodated in a CHRS had a higher level of depression $(M=9.4, S D=3.6)$ than those were accommodated in one $(M=6.4, S D=3.3)$. Significant differences between the two groups also emerged for mean anxiety scores, $F(1,24)=16.0, p<0.01$, with homeless participants not in a hostel exhibiting a higher level of anxiety $(M=13.3, S D=2.9)$ than those who were $(M=8.5, S D=3.1)$.

\subsection{The Interviews}




\subsubsection{Subjective responsibility for their homeless situation}

Table 2 shows how participants attributed subjective responsibility for their homeless situation. If the accumulation of several negative events in their lives is responsible for their homeless situation, then we study the perception these individuals have of their own responsibility in their situation. This responsability could be divided into three types: 1) personal (or internal); 2) personal and external; and (3) external.

\section{Insert Table 2 here}

The two groups differed significantly on personal responsibility, $\chi^{2}(1)=6.52, p<0.05$, as participants who felt personally responsible for their homeless situation were more numerous in the hostel group (60\%) than in the non-hostel group (12.5\%).

We found that only $12.5 \%$ of participants not in a CHRS felt responsible for their homeless situation. The rest of them (87.5\%) attributed their situation either partly or wholly to external factors. Although $50 \%$ of them accepted some degree of responsibility for their accommodation problems, they were nearly unanimous in considering that they would not be in that situation if they had not met with such a dishonest boss or landlord, or if their relations with their family or spouse had not been so chaotic, and so on. However, although these participants did not feel personally responsible for their situation, they did need to give it meaning, and therefore had recourse to a system of external causality. Their speech frequently sounded quite matter of fact when they talked about this environment that had been so unfavourable to them. They could consider themselves to be entirely normal. After all, who would not have become alcoholic after such a bad break? Who would not have lost their job after becoming alcoholic? Without a job, who can go on paying the rent? And yet, while recounting these events enabled them to justify and legitimize their becoming homeless, this way of analysing their situation contributed to a feeling of being misunderstood, which could 
easily turn into a feeling of injustice. These participants therefore described themselves as the victims of a tragic fate.

By contrast, 60\% of participants accommodated in a CHRS felt fully responsible for their homeless situation. Although they cited the same causal events that had led them to their homeless situation, they felt they had played a real part in their becoming homeless. They frequently said, “I shouldn’t have drunk so much. I should have pulled myself together in order to keep my job”, rather than "It's because of alcohol and because of my boss who fired me”. Although this type of personal responsibility went hand in hand with a feeling of guilt, it also fostered the feeling that they were in charge of their own lives, which lessened the risks of mental chaos when they found themselves in a homeless situation.

\subsubsection{Living on the Street}

Table 3 shows the percentages of participants concerned by various forms of suffering and activities linked to life on the street. We then noted the elements the more frequently uttered by the homeless when asked about the difficulties coming from their living conditions.

\section{Insert Table 3 here}

The two groups differed significantly on several points. More participants in the nonCHRS group than in the CHRS group declared that they suffered from their difficult living conditions ( $100 \%$ vs. 50\%), $\chi^{2}(1)=9.91, p<0.01$, feeling physically threatened (43.8\% vs. $0 \%), \chi^{2}(1)=5.99, p<0.05$, and walking around the streets all day (87.5\% vs. $\left.40 \%\right), \chi^{2}(1)=$ 6.52, $p<0.05$. Whereas the latter no longer had to live on the street with all its attendant dangers, the former spoke of how difficult it was to live there, forced as they were to endure it day after day, in constant fear of being attacked. Some say “the street is a jungle, you can’t trust anyone”, or "night is the most dangerous time, you always need to keep an eye open". Both groups reported suffering from boredom and painful loneliness. Participants attempted to alleviate their 
suffering by adopting various behaviours such as walking about, taking alcohol or other drugs, or meeting up with other homeless pals. One of them told me: “This morning, I joined the other homeless on the parking lot, we drank alcohol and had fun. I know it's nothing to be proud of, but I can't spend the whole day alone moping around”. While these routine activities were frequently present among participants sleeping rough or in an emergency night shelter, they were somewhat less frequent among participants accommodated in a long-stay hostel (although the differences on individual items were not statistically significant). These results indicate that being admitted to a CHRS not only leads to a reduction in these behaviours, but also helps to prevent them becoming routine. Massive alcoholism and drug addiction are substantially reduced, and errant behaviour is constrained by being in the hostel ("When I have nothing to do, I hang around, but in the common room”).

\subsubsection{Support from family and friends}

Table 4 shows the percentage of homeless having kept relationships with their family and/or friends after they lost their housing. Here we consider that the relationship still exists when the individual is in touch and is in capacity to ask for help. On the opposite, we also note the percentage of the homeless with no more family or friendly relationships.

\section{Insert Table 4 here}

The homeless condition inevitably questions the lack of social support as no one could rely on their relatives to make up for the lack of housing. Nevertheless, as shown in Table 4, there were significant differences between the two groups, and it is a well-known fact that individuals admitted to long-stay hostels are more likely to benefit from social support (60\% vs. $12.5 \%), \chi^{2}(1)=6.52 p<0.05$.

For participants not in a CHRS, being reduced to living on the street generally coincided with the breaking off of relations with their relatives and friends, if they were not already totally 
isolated. These participants emphasized that breaking off relations in this way was a deliberate act on their part. Feeling ashamed of their situation, they would decide to sever all ties in order not to be pitied by their relatives. We can surmise that their decision not to tell their relatives about their situation enabled them, at least through their memories, to preserve the link and avoid the risk of a fresh disillusion or another breakdown in a relationship. Some participants even said that their relatives might well have helped them if they had been told of their difficulties. This illustrates the fragile and ambivalent nature of ties that may not stand up to the strain of their homeless situation.

This feeling of shame must therefore be taken into account, for these participants often felt dishonoured and subject to disapproval. They no longer felt worthy of keeping in touch with their relatives. Some would say, “I don't want my family to see me in this situation!”, or “I could ask my mother for some help but I’m too ashamed”. By contrast, $60 \%$ of participants living in a CHRS had maintained some form of links with their family or close friends. Their admission to a hostel, their living in respectable conditions, their being on the road to reintegration, enabled them to keep their dignity. Some would say, "I go to the cinema, I go to the restaurant with friends, I’m like everybody else, except that I don’t have my own flat”.

\subsubsection{Reintegration attempts and visions of the future expressed by the homeless participants}

Table 5 shows the percentage of participants who were making steps to become reintegrated and were capable of looking to the future. They are asked on the one hand what steps they're making to find a job, a training course or a housing, and on the other hand how they imagine thelselves in a few months or years.

\section{Insert Table 5 here}


The two groups of differed significantly on these two variables, $\chi^{2}(1)=8.55, p<0.01$, and $\chi^{2}(1)=6.83, p<0.01$. Fewer participants who were not in a CHRS were making steps to become reintegrated (31.25\% vs. $90 \%$ ) and looked to the future (18.75\% vs. $70 \%)$.

Few of the participants who were not in a long-stay hostel were able to look to the future. Some will say “it’s a long time since I've had any future”, or "my grave is my future”, or “ I can't think towards the future, I just try to survive from day to day”. Adopting daily behaviours such as walking around, drinking, meeting up with other homeless persons, and so on, highlighted the difficulty they had thinking constructively about the future. While a clear majority of them declared outright that they were not making any effort to be reintegrated ("I must come to grips with things but it’s too hard , I don’t have the strength” ; “It's easier to let go than try to pull together”), those who were making steps (31.25\%) considered that they could not possibly lead to a positive outcome. They highlighted the fact that without a place to live, it is impossible to find a job, and without a job, it is impossible to afford the rent for a flat. Although some of them stated that they regularly attended employment agencies, they also pointed out that they could not possibly work because of their alcoholism and/or homeless situation. The latter prevented them from keeping up with the pace of work. Some commented, “If I go and see a boss looking all washed up, I won't be credible”, or "If I find a job but am still sleeping rough, I know I'll fall apart in three days”. In the end, all the participants were cruelly aware of the deadlock they were in regarding their social reintegration.

In contrast to these homeless participants still living on the street, those who were accommodated in a CHRS had social reintegration projects and were actively supported by social workers. Ninety per cent of them highlighted the steps they were taking (looking for a job, a training programme, a flat, healthcare, etc.). They were making a genuine attempt to escape their homeless situation. They were determined to succeed, and were involved in some of the activities laid on by the hostel to help them adjust to working life. The goal they had set 
themselves enabled them to fight off boredom and avoid thinking about their situation. They were no longer enmeshed in the immediate issue of how to survive on the street. They had deliberately requested admission to a CHRS, they had been admitted, they had drawn up a reintegration project, and they knew that their stay in the hostel was time limited. They had a definite aim of finding a place to live again. It should be noted that $70 \%$ of these participants looked to the future, unlike those in the other group.

\section{Discussion}

We compared homeless individuals who had been admitted to a long-stay hostel with ones who had not been admitted. Participants who had not been admitted to a CHRS were characterized by high levels of anxiety and depression (cf. Table 1), a feeling of external responsibility (cf. Table 2), and a vagrant lifestyle. They suffered from having to live on the street (cf. Table 3), had no social support (cf. Table 4), made no moves towards reintegration, and were incapable of looking to the future (cf. Table 5).

On one hand, these results show the positive impact of CHRS on the mental health of the homeless. Depression levels revealed greater mental suffering among participants who had not been admitted to a CHRS (9.4 vs. 6.4; Table 1). The relatively low depression score among participants accommodated in a long-stay hostel should be attributed to the level of support that was available there. This support allowed them to maintain their relationships with family and friends (cf. Table 4), and protected them from the way other people looked at them. The structured activities provided by the hostel enabled them to fight off boredom other than by roaming the streets (cf. Table 3). The high level of anxiety among participants who had not been admitted to a CHRS (13.3) (cf. Table 1) can be attributed to their living conditions. We should remember that the adaptive function of anxiety is that it enables people to prepare themselves to face an unknown and potentially threatening situation. It becomes pathological when that 
feeling of threat becomes permanent. The intensity of that anxiety greatly depends on the individual's ability to cope with threats. Forced to survive in the street, these participants could not control their lives. The future looked particularly uncertain to them. Totally unable to overcome their homeless condition, they had no choice but to endure it at the cost of heavy anxiety. The lower level of anxiety among participants living in a CHRS (8.5) was linked to the feeling of comfort and security provided by this hostel. Looked after by social workers, they no longer had to face the day-to-day challenge of surviving the dangers of life on the street. Given an opportunity to look towards the future, they could undertake actions with a very real hope of wresting themselves from their predicament (cf. Table 5).

On the other hand, these results permit to identify the factors involved in the difficulties in acceding to a CHRS. A large proportion of all participants freely admitted to an excessive daily consumption of alcohol and/or drugs: $56.3 \%$ among those not in a CHRS, and $40 \%$ among those were in one (cf. Table 3). It is strictly forbidden to consume toxic substances in these long-stay hostels, and a state of inebriety or high intoxication is a cause of exclusion. In line with this, participants admitted to a CHRS reduce their consumption even after they have left. However, we should also take into account the fact that many participants used the psychoactive effects of these substances to overcome a depressive and/or anxious state. Consuming these substances induces a sort of psychological anaesthesia that enabled them to extract themselves from the socially normative processes of thinking (De Mijolla \& Shentoub, 1973). It therefore allowed them to give meaning to their situation, and to the deadlocks and difficulties they faced throughout their attempts at reintegration. The two groups (CHRS and nonCHRS) differed in the degree of responsibility they felt for their homeless situation. This result is in line with the findings of Astier (2007), Damon (2002), Duvoux (2009), and Soulié (1997). Feeling involved in one's situation and feeling at least partially responsible for it makes it easier to gain access to a CHRS and increases the chances of reintegration. The feeling of being responsible for what 
has happened strengthens people's motivation to solve the problems they face (Brosschot, Gebhardt, \& Godaert, 1994) and leads to an improvement in their emotional wellbeing (Bruchon-Schweitzer, 2002). By contrast, individuals with no feeling of control over their existence are more likely to resign themselves to their living conditions (Seligman, 1975).

The constant instability of the homeless living in the street therefore has an impact on their mental health and complicates the possibilities of entering into a dynamic of insertion. We note that integration actions initially planned for all of the homeless are not offered to everyone. In CHRS admission criteria are insidious, such as the necessity of planning for the future and building an integration project (Lallemand et Catahier, 2004), or the degree of employability of the person (Pelège, 2004), or even the capacity of following life's rules in collectivity. Therefore, only the most competent homeless manage to gain an access to integration structures. This impossibility for chronic homeless people to overcome the obstacles to their reintegration takes one back to the failure of the so-called «tiered services », which aim at housing as their final objective in the treatment of homelessness (Pleace, 2008). Therefore the stability and security brought by a fixed abode appears as a basic condition for the homeless to put an end to their survival behaviours in the street and their massive alcoholism, and for their access to a dynamic of healthcare and social insertion.

\section{Conclusion}

The aim of the present study was to shed light on the issue of reintegrating the homeless population. To do this, a group of 16 homeless persons was compared with a group of 10 individuals living in a long-stay hostel.

The results allowed us to identify several factors that impede the rehabilitation of the homeless population. High depression and anxiety levels, together with various features such as a vagrant lifestyle, a lack of social support, and the allocation of an external type of 
responsibility, were significantly linked to the difficulty of gaining access to a CHRS. An accumulation of these negative elements therefore tends to prevent a proportion of the homeless population from benefitting from opportunities for social reintegration provided by the social welfare system. Anxiety and depression were found to be two significant variables with respect to the difficulties encountered by homeless persons in achieving social reintegration. This result should be set against the differint lifestyles of these two populations. Individuals attending emergency shelters or living rough belong to the most socially maladjusted portion of the homeless population. They survive from day to day without any possibility of projecting themselves into the future, they adopt aggravated behaviours of alcohol/drug abuse, they wander around the streets, and frequent other homeless people all behaviours indicative of impaired mental elaboration. The participants admitted to a CHRS found in this institution a way of life that protected them from the instability, insecurity and harsh living conditions endured by the other group. The support provided by these structures inhibits the socially deviant behaviours of homeless people, and promotes their entry into a dynamic process of social reintegration. They are able to maintain an acceptable level of personal hygiene, and reestablish contact with their families. They gradually invest themselves in society in order to find a place within it. The hostel becomes a resource for its residents. It is a stepping stone, helping them to rebuild their lives and then extract themselves from their homeless situation.

These results are consistent with the literature regarding the increased prevalence of psychiatric disorders (depression, anxiety) and the seriousness of alcoholism/addiction problems. Our sample was not large enough to allow for a valid comparison of our results, in terms of prevalence, with existing studies. Our results do, however, give food for thought concerning the inaccessibility of reintegration schemes for certain individuals, possible improvements to the system of therapeutic and social support for homeless people, and more targeted prevention of psychiatric disorders within this vulnerable population. In order to cope 
with their difficult living conditions, homeless people tend to adopt set behavioural patterns that unfortunately consign them to even greater exclusion. We need to increase the number and quality of facilities offering homeless individuals genuine mentoring. Only long-term psychosocial monitoring can help them acquire the routine of day-to-day survival on the street. It is only by treating their symptoms of depression and anxiety, and by promoting their involvement in their daily lives, that these homeless persons will be able to regain confidence in their future and embark on a project of social reintegration.

The perspectives of this study are in favor of the approach "Housing First” developed by Tsemberis (2010). Here, housing is not considered as a single purpose but as a basic requirement for all insertion actions and care. So we don't wait for the homeless to be perfect, that they bend to the rules and that they cross every step towards housing but that they remain ordinary.

In order to suit the most desocialized homeless the measures of Housing First must offer a complete program of medico-social care, a flexible and intensive personal support as well as a narrow collaboration with the departments of mental care and addiction.The stability of this program will enable the professionals to build up trust relationships essential to a good evaluation and a care adapted to the homeless. The return to stable accomodation is the starting point to integration. It brings security and predictability, it improves medical treatments efficiency and allows the person to cope with the various aspects of their life. The measures must further family support (for instance by paying the homeless a train ticket so he can take part in a family meeting) and social support (for instance by encouraging the person to take part in social activities and in his neighbourhood life). The first experiments of Housing First proved to be positive for the people's mental health (Pleace \& Quilgars, 2013) and efficient in the treatment of homelessness in the States (Padgett, Heywood \& Temberis, 2015) and in Europe (Pleace \& Bretherton, 2013). Therefore, it is necessary to step aside from the «tiered » 
approaches and to develop processes inspired by Housing First to cope with homelessness in France.

\section{References}

American Psychiatric Association (1995). DSM-IV: Diagnostic and statistical manual of mental disorders. Washington, DC: American Psychiatric Association.

Astier, I. (2007). Les nouvelles règles du social. Paris, France: Presses Universitaires de France.

Bassuk, E. L., Rubin, L., \& Lauriat, A. (1984). Is homelessness a mental health problem? The American Journal of Psychiatry, 141, 1546-1550. doi:10.1176/ajp.141.12.1546

Beauvois, J. E., \& Dubois, N. (1988). The norm of internality in the explanation of psychological events. European Journal of Social Psychology, 18, 299-316. doi:10.1002/ejsp.2420180402

Benslama, F., (2005). A psychopathology of the phenomenum of wandering. Its relations with modern culture. Annales Médico-psychologiques, 163, 132-137. doi:10.1016/j.amp.2003.10.019

Brosschot, J. F., Gebhardt, W. A., Godaert, \& G. L. R. (1994). Internal, powerful others and chance locus of control: Relationships with personality, coping, stress and health. Personality and Individual Differences, 16, 839-852. doi:10.1016/01918869(94)90228-3

Bruchon-Schweitzer, M. (2002). Psychologie de la santé: modèles, concepts et methods. Paris, France: Dunod.

Castel, R. (1995). Les Métamorphoses de la question sociale: Une chronique du salariat. Paris, 
France: Fayard.

Chamberlain, C., \& MacKenzie, D. (2006). Homeless careers: A framework for intervention. Australian Social Work, 59, 198-212. DOI: 10.1080/03124070600651903

Chevalier, J., Langlard, G., Le Maléfan, P. et Bouteyre, E. (2017). Defense strategies and social exclusion: the paradoxical over-adaptation of SDF persons. Bulletin de psychologie, 547(1), 33-44. DOI : 10.3917/bupsy.547.0033

Clapham, D. F. (2003). Pathways approaches to homelessness research. Journal of Community and Applied Social Psychology, 13, 119-127. doi:10.1002/casp.717

Cohen, C. I., \& Thompson, K. S. (1992). Homeless mentally ill or mentally ill homeless? American Journal of Psychiatry, 149, 816-823. DOI: 10.1176/ajp.149.6.816

Combaluzier, S., \& Pedinielli, J. L. (2003). Study of the influence of mental disorders on the problems of social rehabilitation. Annales Médico-psychologiques, 161, 31-37. doi:10.1016/S0003-4487(02)00224-X

Damon, J. (2002). La question SDF: Critique d'une action publique. Paris, France: Presses Universitaires de France.

De Mijolla, A., \& Shentoub, S.A. (1973). Pour une psychanalyse de l'alcoolisme. Paris, France: Payot.

Duvoux, N. (2009). L'autonomie des assistés: Sociologie des politiques d'insertion. Paris, France: Presses Universitaires de France.

Fazel, S., Khosla, V., Doll, H., \& Geddes, J. (2008). The prevalence of mental disorders among the homeless in western countries: Systematic review and meta-regression analysis. PLOS Medicine, 5, 1670-1680. doi:10.1371/journal.pmed.0050225 
Fichter, M. M., \& Quadflieg, N. (2001). Prevalence of mental illness in homeless men in Munich, Germany: Results from a representative sample. Acta Psychiatrica Scandinavica, 103, 94-104. PMID: 11167311

Guesdon, J., \& Roelandt, J. L. (1998). An enquiry into mental health of homeless people in Lille: Excluded people. L'Information Psychiatrique, 74, 343-357.

Heider, F. (1958). The psychology of interpersonal relations. New York, NY: Wiley.

Kovess, V., \& Mangin Lazarus, C. (1999). The prevalence of psychiatric disorders and use of care by homeless people in Paris. Social Psychiatry and Psychiatric Epidemiology, 34, 580-587. doi:10.1007/s001270050178

Lallemand, D., \& Catahier, S. (2004). Guide des CHRS (3ème edition). Paris, France: Editions ASH.

Langlard, G. (2017). Mental health approach of homeless people in relation to the type of care offered by the plan of social assistance (Thesis). Rouen, France: University or Rouen.

Langlard, G., \& Bouteyre, E. (2013). Comparative study of ten homeless subjects attending emergency shelter and ten homeless subjects living on the streets only: Acceptance and rejection of the emergency shelter. Annales Médico-psychologiques, 171, 531-537. doi:10.1016/j.amp.2012.10.015

Lepine, J. P., Godchau, M., Brun, P., \& Lempérière, T. (1985). Evaluation of anxiety and depression among patients hospitalized on an internal medicine service. Annales Médico-psychologiques, 143, 175-189. PMID: 4037594

Noirot, M.-N., Descarpentries, F., \& Mercuel, A. (2000). Assistance refusal for the homeless people. Psychopathology and ethics: Freedom or interventionism? L'Évolution Psychiatrique, 65, 763-771. doi:10.1016/S0014-3855(01)80006-2 
Padgett, D. K., Heywood, B. F., \& Tsemberis, S. J. (2015). Housing first: ending homelessness, transforming systems and changing lives. Oxford, UK: Oxford University.

Pelège, P. (2004). Hébergement et reinsertion sociale, les CHRS: dispositive, usagers, intervenants. Paris, France: Dunod.

Pleace, N. (2008). Effective services for substance misuse and homelessness in scotland: evidence from an international review. Edinburgh, UK: Scottish Government Social Research.

Pleace, N., \& Quilgars, D. (2013). Improving health and social integration throught housing first: a review. Brussels, Belgium: DIHAL/FEANTSA.

Seligman, M. E. P. (1975). Helplessness: On depression, development, and death (Series of books in psychology). San Francisco, CA: W. H. Freeman

Soulié, C. (1997). Le classement des sans-abri. Actes de la Recherche en Sciences Sociales, 118, 69-80. doi:10.3406/arss.1997.3223

Testé, B. (2009). Norm of internality and liberalism: Impact of the judgmental context on the valorization of internal explanations. Psychologie Française, 54, 137-152. doi:10.1016/j.psfr.2009.03.001

Tsemberis, S. (2010). Housing first: ending homelessness. Promoting recovery and reducing costs. In I. Gould Ellen \& B. O’Flaherty (eds). How to house the homeless. New York, NY: Russell Sage Foundation.

Vandecasteele, I., \& Lefebvre, A. (2006). De la fragilisation à la rupture du lien social: Approche clinique des impacts psychiques de la précarité et du processus d'exclusion sociale. Cahiers de Psychologie Clinique, 26, 137-162. doi:10.3917/сpc.026.0137 
Vexliard, A. (1957). Le clochard: Etude de psychologie sociale. Bruges, Belgique: Desclée de Brouwer.

Wresinski, J. (1987, February 28). Grande pauvreté et précarité économique et sociale (Rapport). Paris, France : Journal Officiel du 28 février 1987.

Zigmond, A. S., \& Snaith, R. P. (1983). The Hospital Anxiety and Depression Scale. Acta Psychiatrica Scandinavica, 67, 361-370. PMID: 6880820

Conflicts of interest: none. 
Table 1

Mean (standard deviation) depression and anxiety scores, according to admission/nonadmission to a long-stay hostel (CHRS)

Participants not admitted to Participants admitted

\begin{tabular}{lccc} 
& a CHRS & to a CHRS & $F_{(1,24)}$ \\
\hline Depression & $9.4(3.6)$ & $6.4(3.3)$ & $4.66^{*}$ \\
Anxiety & $13.3(2.9)$ & $8.5(3.1)$ & $16.0^{* *}$ \\
\hline
\end{tabular}

$* p<0.05 . * * p<0.01$. 
Table 2

Distribution of the two groups as a function of the type of subjective responsibility to which their homeless situation is attributed.

No. participants

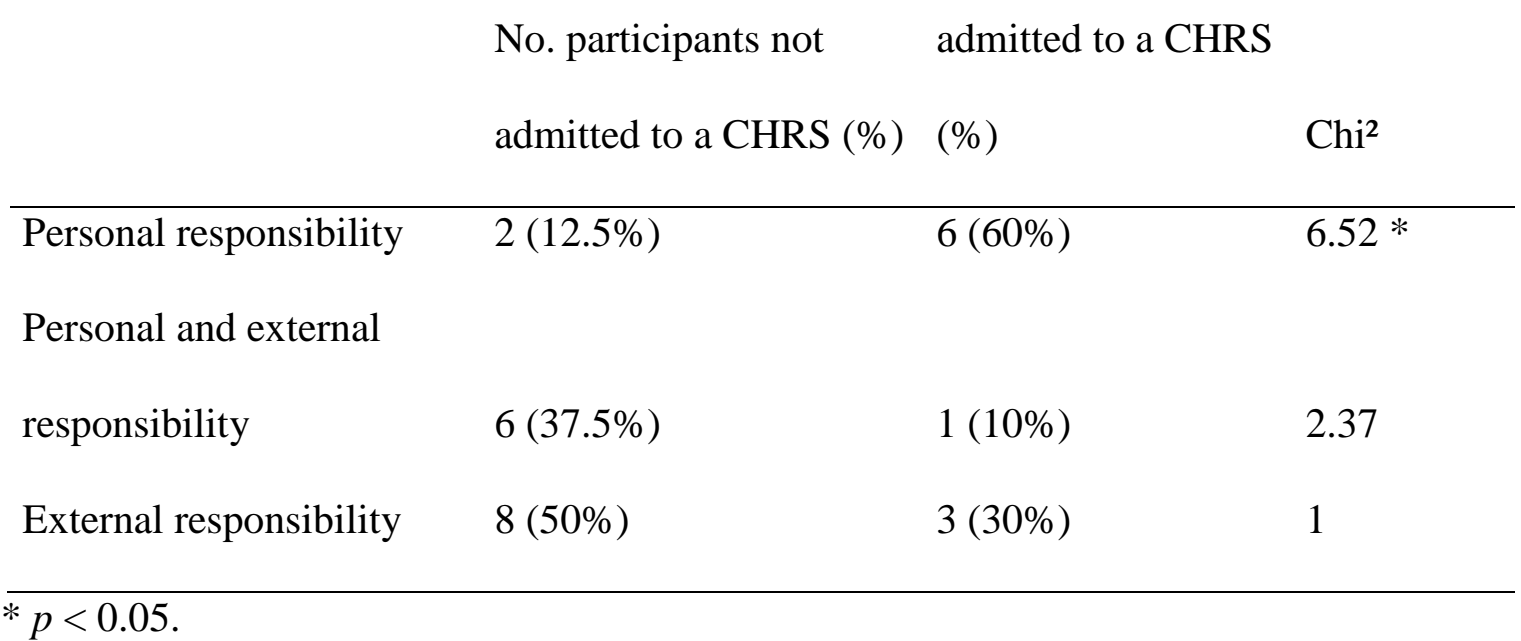


Table 3

Percentage of homeless persons suffering from aspects of life on the street, depending on their admission or nonadmission to a long-stay hostel (CHRS)

\begin{tabular}{llll}
\hline & No. participants not & No. participants & \\
& admitted to a CHRS & admitted to a & \\
& $(\%)$ & CHRS (\%) & Chi $^{2}$ \\
\hline Suffering from difficult living & $16(100 \%)$ & $5(50 \%)$ & $9.91 * *$ \\
conditions & $13(81.3 \%)$ & $7(70 \%)$ & 0.44 \\
Suffering from boredom & $8(50 \%)$ & $2(20 \%)$ & 2.34 \\
Suffering from other people’s gaze & $6(37.5 \%)$ & $4(40 \%)$ & 0.06 \\
Suffering from loneliness & $7(43.8 \%)$ & $0(0 \%)$ & 0.65 \\
Feeling physically threatened & $9(56.25 \%)$ & $4(40 \%)$ & $6.52 *$ \\
Taking alcohol/drugs everyday & $14(87.5 \%)$ & $4(40 \%)$ & 1.53 \\
Wandering around the streets & $7(43.75 \%)$ & $2(20 \%)$ & \\
\hline Frequenting other homeless persons & & & \\
\hline
\end{tabular}


Table 4

Percentage of homeless individuals having relationships with family and/or friends, according to admission/nonadmission to a long-stay hostel (CHRS)

\begin{tabular}{llll}
\hline & No. participants not & No. participants & \\
& admitted to a CHRS & admitted to an & \\
& $(\%)$ & CHRS (\%) & Chi $^{2}$ \\
\hline Relationship with friends and/or & & & \\
family & $2(12.5 \%)$ & $6(60 \%)$ & $6.52 *$ \\
$* p<0.05$. & & &
\end{tabular}




\section{Table 5}

Percentage of homeless individuals making steps to be rehabilitated and looking to the future, according to admission/nonadmission to along-stay hostel (CHRS)

\begin{tabular}{llll}
\hline & $\begin{array}{l}\text { No. participants not } \\
\text { admitted to a CHRS }\end{array}$ & \multicolumn{2}{l}{ No. participants } \\
& $(\%)$ & CHRS (\%) & Chi $^{2}$ \\
\hline Taking steps to be reintegrated & $5(31.25 \%)$ & $9(90 \%)$ & $8.55 * *$ \\
Looking to the future & $3(18.75 \%)$ & $7(70 \%)$ & $6.83 * *$ \\
\hline$* * p<0.01$. & & & \\
\hline
\end{tabular}

